\title{
O Cinema e sua dimensão estético-pedagógica: Bacurau e a Lógica Exúlica
}

iD Ana Vitória Luiz e Silva Prudente ${ }^{1}$, iD Ellen de Lima Souza ${ }^{2}$

1, 2 Universidade Federal de São Paulo - UNIFESP. Escola de Filosofia, Letras e Ciências Humanas/Programa de PósGraduação em Educação. Estrada do Caminho Velho, 333, Jardim Nova Cidade. Guarulhos - SP. Brasil.

Autor para correspondência/Author for correspondence: ana.vitoriaprudente@gmail.com

RESUMO. O artigo “O Cinema e sua dimensão estéticopedagógica: Bacurau e a Lógica Exúlica" tem como objetivo expressar a dimensão estético-pedagógica do cinema, atingindo muitos tecidos sociais por ser uma estrutura que permite uma ação contínua na produção da subjetividade e na formação do gosto e do interesse de seus agentes consumidores, por meio das representações e representatividades possíveis. Utilizamos como metodologia a Lógica Exúlica, de Souza (2016), para compreender as relações entre coletividade, infância, as marcações de gênero, a compreensão de 'outro' e a cidade, centralizando o saber na encruzilhada. Esta interlocução forja possibilidades de rompimento com a colonialidade do poder, viabilizando circularidade de saberes, que em si já propõe uma quebra com o raciocínio cartesiano que se baseia em uma construção imperialista, colonial, que privilegia: o eurocentrismo, em detrimento das cosmopercepções africanas, afrodiaspóricas e indígenas; o adultocentrismo, desconsiderando os saberes infantis e as práticas possíveis dos idosos. Mostrando-se, dessa forma, com um viés racista, utilitarista e capitalístico. É na retirada do ou, para o acréscimo do $e$, na valorização da somatória, que se observa que não há essa ordem de importância que o euro-hétero-macho-autoritário, de Prudente (2019), propõe.

Palavras-chave: dimensão estético-pedagógica, lógica exúlica, infâncias, bacurau, saber na encruzilhada. 


\title{
Cinema and its aesthetic-pedagogical dimension: Bacurau and the Exulic Logic
}

\begin{abstract}
The article "Cinema and its aesthetic-pedagogical dimension: Bacurau and the Exulic Logic" aims to express the aesthetic-pedagogical dimension of cinema, reaching many social fabrics for being a structure that allows a continuous action in the production of subjectivity and in the formation of taste and interest of its consuming agents, through possible representativeness and representation. We use the Exulic Logic as a methodology Souza (2016) to understand the relationships between collectivity, childhood, gender markings, the understanding of 'the other' and the city, centralizing knowledge at the crossroads. This dialogue forges possibilities of breaking away from the coloniality of power, enabling circularity of knowledge, which in itself already proposes a break with Cartesian reasoning, which is based on an imperialist, colonial construction that privileges: Eurocentrism to the detriment of African, Aphrodiasporic and indigenous cosmoperceptions; adultcentrism, disregarding children's knowledge and the possible practices of the elderly, thus, with a racist, utilitarian and capitalistic bias. It is in the removal of or, for the addition of and, in the valuation of the sum, that it is observed that there is no such order of importance that the Euro-straight-maleauthoritarian Prudente (2019) proposes.
\end{abstract}

Keywords: aesthetic-pedagogical dimension, exulic logic, childhoods, bacurau, knowledge at the crossroads.

\begin{tabular}{|l|l|l|l|l|l|l|} 
RBEC & Tocantinópolis/Brasil & v. 6 & e12372 & $10.20873 /$ uft.rbec.e12372 & 2021 & ISSN: 2525-4863 \\
\hline
\end{tabular}




\section{El cine y su dimensión estético-pedagógica: Bacurau y la lógica Exulic}

RESUMEN. El artículo "El cine y su dimensión estéticopedagógica: Bacurau y la lógica Exulic" pretende expresar la dimensión estético-pedagógica del cine por ser una estructura que permite una acción continua en la producción de subjetividad y en la formación del gusto e interés de sus agentes consumidores, a través de posibles representaciones y representatividad. Utilizamos la Lógica Exulic como metodología Souza (2016) para entender las relaciones entre colectividad, infancia, marcas de género, la comprensión del 'otro'; y la ciudad, centralizando el conocimiento en la encrucijada. Esta interlocución forja posibilidades de ruptura con la colonialidad del poder, posibilitando la circularidad del conocimiento, que en sí misma ya propone una ruptura con el razonamiento cartesiano que se fundamenta en una construcción imperialista, colonial, que privilegia: Eurocentrismo en detrimento de las cosmopercepciones africanas, afrodiaspóricas e indígenas; adultcentrismo, desconociendo los conocimientos de los niños y las posibles prácticas de los ancianos, mostrándose así con un sesgo racista, utilitario y capitalista. Es en la eliminación de o, por la suma de y, en la valoración de la suma, que se observa que no existe tal orden de importancia que propone el euro-heterosexual-masculino-autoritario Prudente (2019).

Palabras clave: dimensión estético-pedagógica, lógica exúlica, infancia, bacurau, conocimiento en la encrucijada.

\begin{tabular}{|l|l|l|l|l|l|l|} 
RBEC & Tocantinópolis/Brasil & v. 6 & e12372 & $10.20873 /$ uft.rbec.e12372 & 2021 & ISSN: 2525-4863 \\
\hline
\end{tabular}




\section{Le cinéma et sa dimension esthético-pédagogique: Bacurau et la logique exulique}

RÉSUMÉ: L'article «Le cinéma et sa dimension esthéticopédagogique: Bacurau et la logique exulique» express la dimension esthético-pédagogique du cinéma, une structure qui permet une action continue dans la production de subjectivité et dans la formation du goût et de l'intérêt de ses consommateurs, à travers les représentations et représentativité possibles. Nous avons utilisé l'Exulic Logic comme méthodologie Souza (2016) pour comprendre les relations entre la collectivité, l'enfance, les marques de genre, la compréhension de «l'autre» et la ville, en centralisant les savoirs à la croisée des chemins. Cette interlocution forge des possibilités de rupture avec la colonialité du pouvoir, permettant la circularité du savoir, qui en elle-même propose déjà une rupture avec le raisonnement cartésien qui s'appuie sur une construction impérialiste, coloniale, qui privilégie: l'urocentrisme au détriment de perceptions cosmiques l'Afrique et de l'aphrodiaspora; le centrisme des adultes, faisant fi des connaissances des enfants et des pratiques possibles des personnes âgées, se montrant ainsi avec un parti pris raciste, utilitariste et capitaliste. C'est dans la suppression ou, pour l'ajout de et, que l'on constate qu'il n'y a pas un tel ordre d'importance que propose l'Euro-hétéro-masculinautoritaire Prudente (2019).

Mots-clés: dimension esthético-pédagogique, logique exulique, enfances, bacurau, savoirs à la croisée des chemins. 


\section{O Cinema e sua dimensão estético- pedagógica}

$\mathrm{Na}$ obra, "Dialética do Esclarecimento" (1985), escrita por Adorno e Horkheimer, desponta o termo indústria cultural, a partir desses filósofos cria-se um modo de pensar e relacionar-se com a arte novo, ao longo da contemporaneidade. A indústria cultural, segundo esses autores, tem uma estrutura que permite uma ação contínua na produção da subjetividade e na formação do gosto e do interesse de seus agentes consumidores. Pois, se de um lado entendemos que o termo 'indústria' é uma expressão da automação e agilidade para a produção e distribuição que favorece o capital, em nome de um viés mercantilista; sabemos que 'cultura' pode ser compreendida como um conjunto de elementos que contemplam o sentimento e a existência de um povo - de forma material e imaterial. A partir do avanço industrial no século XIX, os meios de comunicação de massa em todo o mundo entraram em processo de desenvolvimento. E não à toa, o filósofo Huizinga (2010) nos aponta que "o século XIX perdeu grande número dos elementos lúdicos que caracterizavam as épocas anteriores" (p. 217).
Os veículos de comunicação em massa atuam atingindo um grande e diversificado público, partindo de um único transmissor, agem em nosso imaginário por meio do desenvolvimento poético. Sendo, a cultura de massa uma das principais articuladoras de um modelo de organização econômica que produz uma subjetividade capitalista, auxiliando na formação identitária a partir de um viés mercantil. Huizinga (2010) nos lembra que a relação das Artes com a tecnologia moderna é de propinquidade:

A arte está muito mais sujeita do que a ciência à influência deletéria da técnica moderna. A mecanização, a publicidade e o desejo de fazer sensação atingem muito mais fortemente a arte, porque a regra geral produz diretamente para 0 mercado e pode escolher livremente entre todas as técnicas que no momento se encontram disponíveis. (Huizinga, 2010, p. 224-225).

A representação artística, presente desde o período das artes rupestres, faz parte da formação identitária humana. Desde os períodos mais remotos da civilização, nosso constructo se dá pela forma com que nos vemos e somos vistos, criando assim os conceitos de individualidade e de coletividade, facilitando ou não ao pertencimento a determinados grupos étnicos, ou categorias ligadas a etariedade, gênero, sexualidade e 
credo. Donis A. Dondis (1991) nos lembra que a linguagem é um recurso de comunicação próprio do ser humano, e não à toa houve uma evolução juntamente com o progresso das ferramentas tecnológicas. Fomos da vocalização à construção de grafismos, da imagem entendida - hoje como primitiva à escrita, da escrita aos recursos tecnológicos de audiovisual e mídias em geral. A imagem, principalmente na contemporaneidade, é uma importante forma de pensar e de construir pensamentos, é uma linguagem em si, ao se considerar o mass medias um fenômeno tipicamente contemporâneo. No livro "Sintaxe da linguagem visual", Donis A. Dondis (1991) rememora que "A arte e o significado da arte, a forma e a função do componente visual da expressão e da comunicação, passaram por uma profunda transformação na era tecnológica, sem que se tenha verificado uma modificação correspondente na estética da arte" (p. 01).

O fenômeno da indústria cultural causa uma radical transformação na dinâmica de produção e distribuição artística, pois direcionar a produção artística pode significar - em algumas instâncias - uma forma de direcionar os rumos da sociedade. O cinema, um fenômeno que nasce na era industrial é uma expressão artística que surge, a princípio, com a tentativa de aproximar as representações do real, utilizando-se do movimento que a sequência fotográfica pode gerar, até eventualmente chegar à filmagem por continuidade o que permite a mimetização; a história do cinema passa por diversas expressões de linguagem, do cinema mudo ao expressionismo, do bangbang ao naturalismo, as formas de comunicar por meio da sétima arte são inúmeras e ainda não foram esgotadas.

Considerando, portanto, sua competência informacional, que está alicerçada nas quatro dimensões: técnica, estética, ética e política, o audiovisual possibilita a promoção da cidadania; como os filmes podem ser amplamente difundidos, enquanto um produto da indústria cultural, há essa possibilidade de que as produções cinematográficas façam parte da construção social, identitária e política das sociedades. E nesse sentido, a cientista da computação Adriana Bogliolio Sirihal Duarte nos aponta que:

... sob a ótica de processo de busca de informação para a construção de conhecimento vai além da busca de respostas às perguntas ao incluir 0 uso, a interpretação, a busca de significados e a construção de modelos mentais. A partir de informações coletadas e compreendidas, o usuário nesse nível de competência informacional é capaz de construir conhecimento (Duarte, 2007, p. 111). 
Há, portanto, também, uma dimensão pedagógica nas produções artísticas cinematográficas; inegavelmente, o cinema constrói e atua na Educação, uma vez que o ser humano consegue por intermédio dessa linguagem não só produzir o conhecimento, mas, também, difundir e utilizar para o desenvolvimento pessoal ou para a comunidade no qual está inserido. Afinal, no cinema a estética atinge, também, o campo pedagógico, no qual se exige uma alfabetização visual que expanda a leitura de outras possibilidades de dinâmicas sociais/políticas/culturais por intermédio das imagens sugeridas pelos filmes. O cinema pode favorecer o contato com outras cosmovisões, aproximando ao que Boaventura de Sousa Santos (2007) aborda com seu conceito de e cologia de $\mathrm{s}$ aberes o reconhecimento da heterogenia dos conhecimentos, como uma proposta à justiça cognitiva. A partir da alfabetização visual é possível construir um léxico que proporciona a reconstrução epistemológica. O audiovisual propicia o confronto dos conhecimentos regulares e os conhecimentos emancipadores, viabilizando a propagação de outras formas de saber e por consequência atingindo o aumento da representatividade dos grupos minoritários, pela expressão da diversidade nesse espaço de saber e poder. As produções cinematográficas enquanto meio para trabalhar e lidar com a sensibilidade, e considerando sua potência formadora, têm, portanto, uma dimensão estéticopedagógica - que traz um processo de transmissão de saber e do conhecimento que valorize os contextos pluriculturais, considerando o lúdico, a sensibilidade, a criatividade, a solidariedade, que implica no resgate dos aspectos humanistas, culturais e sociais, que por vezes ficaram em detrimento da tecnicidade.

Nesse sentido, quando se discute a colonização dos saberes, o cinema também tem sua importância uma vez que essa linguagem surge no Brasil a partir do colonialismo cultural, e não à toa a história do cinema brasileiro tem passado por transformações, e uma de suas marcas é o Cinema Novo, reinventando-se e se apoiando nos alicerces ético e político, avançando na busca por expressar e representar de forma diversa um povo tão múltiplo.

O Cinema Novo surge em uma situação política tensa, e pode ser contextualizado no quadro históricopolítico marcado pelo populismo do final da década de cinquenta e início da década de sessenta, além da ditadura militar de 1964 que se prolongou até 1985. Nesse período a indústria cultural passava por 
transformações, inclusive, do ponto de vista técnico, que permitiu a criação de uma nova estética visual e sonora, que de alguma forma propiciou uma ruptura com a proposta de um cinema como objeto de consumo subordinado ao colonialismo. Em um país de tantas desigualdades, o cinema pode ser um veículo de denúncia, um horizonte para uma visão mais crítica dos panoramas sociais, políticos, econômicos, culturais e identitários. O engendrar da arte e da política convergiu para o Cinema Novo. O cineasta Celso Luiz Prudente (2019), lembra-nos a concepção estética e o contexto político, para a linguagem brasileira, o cinema novo.

\begin{abstract}
Nota-se no cinema novismo influência marxista de tal sorte que para tal se construir um comportamento estético em que o branco representava a burguesia e seus valores e o negro o proletariado com a cultura das lutas de classes, razão pela qual o negro e a sua cultura constituíram o referencial estético do cinema novo. (Prudente, 2019, p. 48).
\end{abstract}

Cabe destacar que as produções nacionais podem pautar denúncias das desigualdades e anúncios de re-existência. No presente artigo destacamos Bacurau (2019), um filme nacional, de Kleber Mendonça Filho e Juliano Dornelles, que alcançou projeções significativas entre o público e a crítica, trazendo a tônica da construção e desconstrução da História. O objetivo do presente artigo é apresentar a dimensão estético-pedagógica do cinema, observando se há no filme "Bacurau" a possibilidade de ser utilizado na formação de professoras/es da educação básica. Propõe-se avaliar se é possível utilizar esse filme como um exemplo, de produção audiovisual, que sugira uma quebra com o plano cartesiano de valoração de raça, classe, gênero e etariedade, sendo essa uma sistemática de poder que enaltece a branquitude, apoia o adultocentrismo, invisibiliza a presença da mulher e subjuga aquele que é colocado à margem, que é assimilado enquanto periférico. Para tanto, utilizaremos a lógica exúlica, de Souza (2016), como metodologia, para compreender as relações entre coletividade, infância, as marcações de gênero, a compreensão de 'outro' e a cidade, no filme, centralizando o saber na encruzilhada.

\section{Bacurau e a lógica exúlica nas relações entre coletividade, infância, as marcações de gênero, a compreensão de 'outro' e a cidade: o saber na encruzilhada}

O filme faz parte dessa transformação nas produções nacionais, ao colocar em cena uma cidade fictícia, em 
que um povo sobrevive ao descaso das autoridades, e sua perseverança se realiza por intermédio da diversidade que se sustenta na união. E a aproximação política, poética e social entre o filme e a realidade, apesar da distância de seus planos de existência, é o fato de o filme retratar uma cidade pequena de poucos habitantes, o que representa fielmente a expressão geopolítica do nosso país, em que a maior parte dos municípios tem menos de vinte mil pessoas.

Segundo o IBGE, 324 municípios têm mais de 100 mil habitantes. Juntos eles são apenas 5,8\% do total de 5.570 municípios do país, mas respondem por $57,4 \%$ da população brasileira ou 120,7 milhões de habitantes, sendo que 48 deles têm mais de 500 mil habitantes. Por outro lado, 3.670 municípios - 68,2\% do total - são habitados por menos de 20 mil pessoas. Juntos eles têm 32 milhões de habitantes ou 15,2\% da população total do país. (Abdala, Agência Brasil, 2019).

Bacurau é uma obra - que retrata uma pequena cidade contra uma estrutura de poder opressora - de impacto, que mobilizou um contingente representativo em número de espectadores, gerando uma bilheteria de milhões de dólares, ao narrar a história dos esquecidos, a vitória dos invisíveis. E são esses "invisíveis" a maioria da sociedade brasileira, isto é, habitantes de municípios com população inferior a 20 mil habitantes. Almeida e Zamberlan (2020) nos apontam:

... mesmo sem enveredar por uma estética realista, Bacurau é eminentemente provocativo, propositivo e político, com uma forte carga simbólica que resgata não uma ideia de pátria ou nação, mas de povo. A soma da mistura de gêneros com a temática da insurgência de um povo faz de Bacurau um filme único na história do cinema brasileiro. (Almeida \& Zamberlan, 2020, p. 495).

Ou seja, há no filme o reconhecimento da importância do povo, considerando sua diversidade, em uma representação de minorias não como um statement para atender as demandas do que é politicamente correto, mas para abarcar a complexidade que é a coletividade, para além de possibilitar o ganho estético, dentro da expressão visual do diverso.

As personagens, no filme, podem ser compreendidas como arquétipos, representações da constituição de um imaginário coletivo, personas que constituem um povo. E nesses arquétipos a criança representa o mensageiro, aquele que detém um saber, quem traz as informações.

O povo é constituído pelas estruturas institucionais de promoção e manutenção da identidade, formação, cultura, saúde e lazer, como escola, museu, igreja, 
instituições de saúde, prostíbulo, assembleia, meios de comunicação comunitários, que são algumas das estruturas organizacionais apresentadas ao longo do filme. Essa ideia de construção e desconstrução de coletividade quebra com o paradigma de o que é pertencer e o que é ser "estrangeiro" a um grupo. O povo, enquanto organismo social vivo, é constituído a partir de seus ritos: a passagem da infância para a vida adulta, o sair de sua terra natal, ou o regresso à terra natal, o uso de drogas lícitas/ilícitas, a morte, as relações sexuais; e esse ritos todos também são apresentados e desenvolvidos no filme. Essas construções, que marcam a existência de um povo, são responsáveis por alguma coesão entre a diversidade que há nesse coletivo que forma o povo de Bacurau.

Bacurau apresenta a desconstrução e reconstrução de um projeto de nação, mas principalmente desvela uma comunidade. E esse valor que a produção dá a essa temática está exposto nos planos de imagem que privilegiam a coletividade em detrimento do close em única uma personagem, na maior parte dos cortes da produção fílmica, Almeida e Zamberlan (2020) afirmam, "Bacurau realiza um importante deslocamento: da reparação pessoal para a coletiva". Mas, o fato de os planos de imagem não privilegiarem o indivíduo junto ao povo de Bacurau, de maneira alguma expressa a quebra com a individualidade. Fato que se evidencia ao contar e mostrar as histórias do personagem Pacote (Thomas Aquino), conhecido como "Rei do Teco" e que pede, inclusive, para ser não ser lembrado como matador urbano, manifestando a complexidade de sua persona enquanto indivíduo. $\mathrm{O}$ que nos remete ao conceito de rostidade, trabalhado por Judith Butler (2019), que incentiva a ligação entre o discurso e o autor. Temos acesso ao que Pacote fez, quem ele é, o que ele faz agora e qual é a diferença de suas ações ao longo do filme e na história prévia ao que é narrado no filme. É preciso restabelecer quem diz, o que diz e como suportar o que é dito, no campo das ações dessa personagem.

\begin{abstract}
Chegamos a existir, por assim dizer, no momento em que estamos sendo endereçados, e algo sobre nossa existência se mostra precário quando esse endereçamento falha. Mais enfaticamente, no entanto, o que nos vincula moralmente tem a ver com a forma como somos endereçados pelos outros de maneira que não podemos evitar ou prevenir. (Butler, 2019, p. 159).
\end{abstract}

É importante pontuar, também, que se por um lado ao tratar do povoado da cidade, a maioria das cenas privilegia o 
coletivo; por outro lado, podemos observar que ao apresentar e desenvolver as cenas com os 'gringos', participantes do safarihumano, é mais comum nos depararmos com cenas que foquem no indivíduo, apresentando suas ações, reaç ões e rostos diante da vontade de matar, a possibilidade ou impossibilidade de cometer algum assassinato e diante da morte em si. Ainda que eles formem um grupo, ainda que haja coesão nesse coletivo, à individualidade supera o pertencimento ao grupo, estamos diante de um agrupamento, diferente da grupalidade presente na comunidade (fictícia) de Bacurau. Essa compreensão é uma leitura possível, a despeito da cena em que um casal de gringos, ao festejar um assassinato que cometeram, decidem se relacionarem sexualmente. Nessa cena aproxima-se sangue e esperma, trazendo a ideia de morte como pulsão de vida.

Em outra cena, o grupo dos gringos conversam com um casal de brasileiros, dois sudestinos, do Rio de Janeiro e de São Paulo, que eles contrataram para auxiliar na organização do safari; é nesse momento que podemos conhecer de fato esse grupo de antagonistas, quando todos dispostos a mesa tem seus rostos exibidos em close e mostram suas expressões diante do jogo que é, para eles, a possibilidade de matar a diferença; essa é uma sequência de cenas em que o individualidade ganha força, pois pertencer é também se identificar, e em um agrupamento nem todos que atuam no grupo pertencem, de fato, a ele. Nesta sequência podemos compreender mais e melhor os planos das personagens segmentando bem quem é o "eu”, "nós" e "eles" a partir da perspectiva do grupo do safari-humano. A relação desse grupo com a morte, e, portanto, com a vida, entra no conceito de desrealização da perda, trabalhado por Butler (2019):

A desrealização da perda - a
insensibilidade ao sofrimento
humano e à morte - torna-se o
mecanismo de realização da
desumanização. Essa desrealização
não ocorre nem dentro nem fora da
imagem, mas no próprio
enquadramento em que a imagem
está contida. (Butler, 2019, p. 179).

O filme inicia com a volta de uma imigrante, Teresa (Bárbara Colen). Retornando a sua cidade natal, Bacurau, no trajeto ela avista um acidente que espalha pela estrada alguns caixões. Seu regresso acontece em decorrência do velório de sua avó, Dona Carmelita (Lia de Itamaracá). Os caixões na estrada e a morte de uma idosa, matriarca da cidade, já traz a tônica da desconstrução para a reconstrução e apresenta o rompimento com a vida como 
uma trilha para a transformação. Em outra parte, mais adiante na narrativa do filme, temos a cena em que um casal tenta fugir da cidade na busca por salvação individualizada e são mortos pelos antagonistas, antes mesmo do desfecho do roteiro, podemos analisar: para existir é preciso resistir coletivamente.

Se no início somos levados ao velório de Dona Carmelita, uma representação da mãe para um quilombo ${ }^{\mathrm{i}}$, a expressão da matriarca africana que alimenta, sustenta e impulsiona e que falece alimentando a terra de água e prosperidade; no meio somos avisados: não há fuga que leve ao caminho da vida. Com essa percepção podemos observar a encruzilhada se apresentando, na proposição de ambiente de embate e propiciando uma inversão de lógicas, de cosmopercepções, como nos aponta os pesquisadores Simas e Rufino (2018). Assim como o cinema a encruzilhada é educativa:

A pedagogia das encruzilhadas é versada como contragolpe, um projeto político/ epistemelógico/educativo que tem como finalidade principal desobsediar os carregos do racismo/colonialismo através da transgressão do cânone ocidental. Esse projeto compreende uma série de ações táticas, fundamentadas nas culturas de síncope, que operam esculhambando normalizações. Os cruzos atravessam e demarcam zonas de fronteira. Essas zonas cruzadas, fronteiriças são lugares de vazio que serão preenchidos pelos corpos, sons e palavras. Desses preenchimentos emergirão outras possibilidades de invenção da vida firmadas nos tons das diversidades de saberes, das transformações radicais e da justiça cognitiva (Simas \& Rufino, 2018, p. 22).

Neste artigo o cruzo se dá entre educação; infância; comunidade; Bacurau e estética-pedagógica. O filme tem em seu enredo marcos que são ligados à questão etária: o retorno da jovem, a morte da idosa, são os primeiros exemplos. Mas, podemos observar a lógica exúlica, Souza (2016), apresentando-se na narrativa simbólica quando o filme começa, concretamente, a expressar sua problemática, por intermédio da descoberta das crianças na escola: Bacurau saiu dos mapas. A professora Souza e o professor Carvalho nos apontam as relações entre a divindade Exu e a categoria infância, desenvolvendo as noções próprias a lógica exúlica:

... as distintas consistências das infâncias derivadas da lógica de Exu reportam polifonicamente diferentes multiplicidades e singularidades de linhas de devires: gestação, nascimento, infância, adolescência, juventude, adultez, velhice e ancestralização. Essas linhas de devires podem ir e vir, numa perspectiva capaz de sabotar a recognição, a interpretação e a 
representação simbólica eurocêntrica de percepção espaço-temporal. Destarte, o entendimento do que seja "criança" não se constrói, a partir daí, cognitivamente e por intermédio da relação de oposição binária, mas dança conforme a exuberância, a intensidade e a experimentação sempre passageiras daquelas mesmas linhas de devires: ora simultâneas, ora em progressão, porém, não excludentes e experienciáveis em qualquer fluxo de vida. (Souza \& Carvalho, 2021, p. 19).

Exu é o orixá da ordem e ele a estabelece por meio da contradição. Ele é o filho que nasceu antes da própria mãe, e por isso a lógica exúlica, característica, também, das crianças, orienta-se no brincar com o tempo/espaço convencional; questionando, assim, a lógica cartesiana, que se baseia em uma construção imperialista, colonial, que privilegia o adultocentrismo, desconsiderando os saberes infantis e as práticas possíveis dos idosos, mostrando-se com um viés utilitarista, capitalista. Na lógica exúlica temos a retirada do ou, para o acréscimo do $e$, somos somatórias, Exu é o procriador e o procriado; não há antagonismos. É possível compreender, portanto, o gráfico cartesiano que divide idade, raça, gênero e classe, como uma encruzilhada, no qual Exu prostra-se no centro, quebrando com a axiologia que a branquitude eurocentrada propõe. Os professores e pensadores,
Souza e Garcia nos convidam, então, a pensar:

Cabe, então, compreender que na definição do sistema mundo racista/capitalista/cristão/patriarcal/m oderno europeu e às suas formas de perpetuação de violências e lógicas produzidas na dominação do ser, saber e poder cabe lembrar do adultocentrismo, como um valor de perpetuação da transformação das diferenças como sinônimo de desigualdade. (Souza \& Garcia, 2020, no prelo).

Segundo Almeida e Zamberlan (2020), "Lançando mão de figuras míticas, Bacurau, desde o início, assume uma perspectiva mais simbólica que alegórica". No filme as aparições das crianças são sempre reveladoras para a narrativa. $\mathrm{Na}$ construção do roteiro o saber infantil nos apresenta a nossa ingenuidade enquanto adultos no público, fazendo-nos questionar sobre quem é "o outro", o inimigo, o antagonista. Se em um primeiro momento as crianças mostram ao educador Plínio (Wilson Rabelo) a ausência de Bacurau no mapa por satélite, em outro momento elas mostram o enfrentamento do medo como um enfrentamento a um inimigo, o lidar com o escuro é lidar com o desconhecido e se confrontar com o outro.

As crianças nos territórios negros são expressões da subversão desses espaços. São os corpos infantis que expressam a re- 
existência da população a todas as iniquidades impostas por políticas higienistas que alicerçaram quase quatrocentos anos de escravidão e racismo/colonialismo. Assim, brincar coletivamente e reforçar os estados de infâncias é subversão para a libertação, pois o ato de brincar está presente em todas as manifestações culturais negras, (folia de reis; maracatu; maculelê; capoeira, etc.) que, inclusive, podem ser adjetivados como sinônimo de brincar, ou ainda jogar, e seus integrantes de brincantes ou jogadores.

Exu, na sua lógica, orienta-nos a brincar, jogar, dançar com o tempo, porque ele é o orixá que se encontra no centro da encruzilhada, que pode ser traduzido como o lugar das possibilidades. $\mathrm{Na}$ compreensão de Rufino:

Exu é a substância que fundamenta as existências; é a linguagem como um todo. É o pulsar dos mundos, senhor de todas as possibilidades, uma esfera incontrolável, inapreensível e inacabada. Ele é o acontecimento, antes mesmo da inscrição deleuziana, por isso ata-se o verso que aqui abre caminho: "Exu nasceu antes da própria mãe". (Rufino, 2019, p. 24).

Se o cogito cartesiano, que dá validade a uma reflexão binária, fortalece um sistema do Mundo racista/capitalista/cristão/ patriarcal/moderno/ europeu, o " $\mathrm{Eu}$ penso, logo existo!", também, fortalece o adultocentrismo, opondo crianças aos adultos, forjando diferença como sinônimo de desigualdade, impondo subalternidade. Para Senghor (1990) a oposição ao cogito cartesiano está na experiência, que por sua vez é a base da existência, a afirmação da negritude está na lógica do "Eu sinto, eu danço o Outro; eu sou", dessa forma poderíamos traçar uma analogia aos estados de infância que fomentam o brincar que implica em "Quando brincamos, logo nos libertamos" (se brinco, me livro), da adultocentricidade inerente ao carrego colonial.

... o conceito de criança não se constrói pela oposição semântica com o conceito de adulto, mas se revela como construção da possibilidade de trânsito (portanto, categoria não estática), cujo movimento, transitividade e narratividade, segundo a semiótica francesa, se inserem na ordem e na natureza do axé, força vital e de permanente movimentação. A infância, nesta propositura, sob a prescrição da lógica de Exu, reporta não a si mesma, mas evoca, polifonicamente, diferentes enunciados de estado (gestação, nascimento, infância, adolescência, juventude, adultez, velhice e ancestralização), estados a que se pode ir e vir, numa perspectiva capaz de sabotar a cognição, a interpretação e representação simbólica eurocêntrica da percepção do tempo. Destarte, o entendimento do que seja "criança" não se constrói 
cognitivamente por intermédio da relação de oposição, mas passeia por enunciados de estados, ora simultâneos, ora em progressão, não excludentes e experienciáveis em qualquer fase da vida. (Souza, 2016, p. 22).

Em Bacurau o brincar é apresentado como território do descobrir, pois é na brincadeira das crianças que descobrimos os antagonistas. É na encruzilhada que se expõe as vivencias que serão experienciadas pela comunidade adulta, pois é na encruzilhada - entre o iluminado e o escuro, entre o perto e o distante, em uma brincadeira de medo e coragem das crianças - que temos o primeiro assassinato na área urbana de Bacurau. Nesse momento do filme, há a constatação da comunidade de que estão sendo atacados. A morte é um presságio para a nova vida, a de luta contra o inimigo e a união da comunidade em nome da dignidade, mais do que da sobrevivência.

O longa-metragem estreia em um Brasil polarizado politicamente, com acirramentos sociais latentes, mas sugere um Brasil do Futuro que se sustenta em um projeto de comunidade em contraposição à barbárie imperialista exposta na ideia de um safári-humano, que explicita a negligência do Estado e corrupção do poder público. Como evidência Mbembe (2018, p. 18), “racismo é acima de tudo uma tecnologia destinada a permitir o exercício do biopoder, 'este velho direito soberano de matar'. Na economia do biopoder, a função do racismo é regular a distribuição da morte e tornar possíveis as funções assassinas do estado". E o filme vai ao limite do conceito de Necropolítica, cunhado pelo autor, ao escancarar como a linha do equador dita o direito à vida, bem como a cor, a cultura e a nacionalidade. $E$, ainda que no enredo os brasileiros (Antonio Saboiae e Karine Teles), apresentados como sudestinos de classe média, enxerguem-se como pertencentes à branquitude e ao poder imperialista, por se alocarem nos grandes centros urbanos, a realidade que os leva a morte os denuncia como brasileiros, latinos, não-brancos. As personagens morrem ambas com cara de dúvida, afinal não foram racializados em suas socializações. Percepção que nos traz a uma aproximação entre o diretor Kleber Mendonça ao seu conterrâneo, o pedagogo, pesquisador, Paulo Freire, que lembra que devemos falar com a classe trabalhadora, oprimida, e não sobre ela, o autor na pedagogia da libertação pontua que o oprimido em uma educação bancária só busca por se tornar opressor:

Por isso é que esta educação, em que educadores e educandos se fazem sujeitos do seu processo, superando o intelectualismo alienante, superando 
o autoritarismo do educador "bancário", supera também a falsa consciência do mundo. O mundo, agora, já não é algo sobre que se fala com falsas palavras, mas o mediatizador dos sujeitos da educação, a incidência da ação transformadora dos homens, de que resulte a sua humanização. Esta é a razão por que a concepção problematizadora da educação não pode servir ao opressor. Nenhuma "ordem" opressora suportaria que os oprimidos todos passassem a dizer: "Por quê?" (Freire, 2013, p. 159).

No filme, se a criança é a responsável pela transmissão de respostas e descobertas, a escola - por consequência tem uma presença significativa e por isso reiterada, do início ao fim, e sua imagem ganha ainda mais força diante do combate entre o povo de Bacurau e os estrangeiros: a guerra, nesse caso, é formadora. Não à toa, esse fato é a história em curso. Próprio, também, a lógica exúlica, o filme mostra o museu como um ambiente propício para a formação e preparação para a guerra, o que é uma alegoria do futuro como uma instância vigente, inclusive, no passado, apontando que a "radicalidade exige de nós uma 'convivência' maior com a raiz dos problemas" (Freire, 2014, p. 240). A escola é usada como trincheira de guerra, o ônibus escolar também, bem como o museu da cidade. A guerra é a formação da comunidade, é um aprendizado coletivo, um ensinamento compartilhado, a resistência é um saber atemporal.

Chama a atenção a organização da comunidade para a resistência e o uso de armas do museu, talvez fazendo a analogia à história do povoado e à importância de se resistir coletivamente. Na preservação da democracia e dos direitos, a resistência terá mais força quando for coletiva. (Palma, Assis \& Vilaça, 2019, p. 35).

Atendendo, outrossim, às outras demandas das minorias, o filme mostra a força da mulher do início ao fim. A simbólica morte de Dona Carmelita, expressa o poder matriarcal que uma mulher negra traz consigo ao gerar e criar toda uma extensa família, marcada pela diversidade, que não torna questionável o caráter. Com a apresentação de Dona Domingas (Sônia Braga), vemos a mulher nordestina, mostrando a complexidade de uma personagem que como médica exerce o papel do cuidado, mas de maneira enérgica para além do arquétipo maternal, ao mesmo tempo em que lida com o alcoolismo. É ela quem oferece ao sniper americano algo de comer, enquanto ele oferece balas atiradas a distância para os conterrâneos da médica.

Outro elemento significativo é a caracterização dos costumes, de onde se deduz a moral que rege a vida coletiva de Bacurau: não parece 
haver discriminação quanto às relações homoafetivas de Domingas; quanto à presença de uma transexual, que realiza inclusive o importante papel de vigia na entrada da aldeia; quanto à prostituição, que aparece integrada à vida da cidade, ou mesmo quanto ao consumo de álcool ou psicotrópico, que aparece como uma semente consumida pelos moradores e que tem o curioso efeito de estimular a lucidez política, capaz de mobilizar a comunidade para lutar contra os forasteiros e expulsar o prefeito. (Almeida \& Zamberlan, 2020, p. 499).

E quando avaliamos a construção das personagens é preciso que se pontue, também, as noções de sujeito a serem sugeridas, a partir da performatividade de gênero, o que permite uma leitura sobre a personagem Lunga (Silvero Pereira). Antes de sua aparição, gera-se a crença de que ele é uma representação de um cangaceiro, em uma imagem do homem-macho, por meio do discurso dos demais personagens a respeito de Lunga. Mas, o que essa personagem expressa é o impulso pela sobrevivência por meio de uma existência queer, uma personagem que transita na identidade de gênero, quebrando com o binarismo homem/mulher. Estamos assistindo, somos espectadores da fragmentação da cis e heteronormatividade compulsória. A liderança na luta, pela dignidade junto à sobrevivência, é guiada por Lunga, a transgressora fluidez de gênero é também condutora de oposição sagaz e potente, o que o torna responsável pela preparação do povo à resistência, mas sobretudo para o enfrentamento. E nesse caso a discussão de gênero não propõe uma salvação individual ao seu grupo, bem como fica explicito que os ataques não dizem respeito a só uma possibilidade de existência, é um ataque contra a coletividade que é compreendida como antagônica a branquitude do euro-héteromacho-autoritário, como conceitua o professor Celso Prudente (2019). Elucidando que não existe saída individual para problemas sociais, o que nos permite ponderar a possibilidade da outra medida ser o que o professor Celso Prudente (2019) nomeia ibero-ásio-afro-ameríndio, e que se enquadra, também, nas perspectivas de idade e gênero, para além das étnicoraciais. Ao qual é essa articulação que o professor vai sugerir como cinema negro:

Se, para Merleau-Ponty o cinema é uma nova psicologia, em que nele também se compreende o lugar de percepção, o cinema negro vai se mostrar, nessa perspectiva, como um corpo que também ocupa a imagem como expressão de consciência; desta forma, o negro não poderia estar deslocado como mera figuração em favor do protagonismo, da hegemonia euro-hétero-machoautoritária. No cinema negro a construção da imagem positiva darse-á por um processo do resgate do valor da africanidade, enquanto 
epistemologia fundada na cosmovisão do respeito à biodiversidade. (Prudente, 2019, p. 131).

Segundo Freire (1971) "todo ato de pensar exige um sujeito que pensa, um objeto pensado, que mediatiza o primeiro sujeito do segundo, e a comunicação entre ambos, que se dá através de signos linguísticos. O mundo humano é, desta forma, um mundo de comunicação" (p. 44). O pedagogo Paulo Freire, que é pernambucano, assim como os cineastas Kleber Mendonça e Juliano Dornelles, trazia em seus trabalhos o conceito de corporalidade da palavra, ideia que propõe tornar o pensar/dizer em agir, fazendo do exemplo a concretude de qualquer comunicação. É na comunicação que se estabelece as muitas linguagens possíveis, e é por meio dela, também, que se dá a tomada de consciência do eu-histórico, permitindo o despertar para a vocação ontológica de ser e fazer mais e melhor. A ação e a palavra se dão corporalmente, reconhecendo que o corpo se constrói socialmente, para além das individualidades que se pronunciam também.

... o que faço faz meu corpo. O que acho fantástico nisso tudo é que meu corpo consciente está sendo porque faço coisas, porque atuo, porque penso já. A importância do corpo é indiscutível; o corpo move-se, age, rememora a luta de sua libertação, o corpo afinal deseja, aponta, anuncia, protesta, se curva, se ergue, desenha e refaz o mundo. (Freire, 1991, p. 92).

No filme, a corporalidade da palavra está expressa na relação do povo de Bacurau com o prefeito Tony Júnior (Thardelly Lima), que quando vai à cidade fazer campanha e doar alimentos vencidos, todos fecham suas portas e o deixam falando sozinho. No início da obra fílmica somos surpreendidos com a presença de diversos caixões caídos na estrada no caminho de Teresa à Bacurau, pouco após a placa "Bacurau: Se for, vá na paz", somente no final do filme compreendemos que esses caixões foram encomendados pelo prefeito Tony Júnior, que havia compactuado com os projetos assassinos do grupo de estrangeiros. Os cidadãos se unem não só em ideal, mas também em práticas, quando mostram sua insatisfação e o reconhecimento de que o prefeito como agente público do Município não atende as necessidades do povo, quem ele teoricamente deveria representar.

A necropolítica é respondida com o alijamento do prefeito, a corporalidade da palavra se dá quando Teco bagunça seu cabelo e lhe bate na cara, enquanto o educador Plínio avisa que o prefeito irá 
morrer, uma vez que a população está sob o efeito de fortes psicotrópicos. O prefeito, então, é alijado seminu, usando uma máscara, sob um burrinho que o encaminha para o seu destino longe da população de Bacurau que se despede com o olhar quente de raiva e com o silêncio gritante de um povo que não aceita mais humilhações, que não permite sua desumanização e a destituição da dignidade humana. Kleber Mendonça Filho e Juliano Dornelles fortalecem, ainda mais, suas relações com Pernambuco e, também, com o Brasil ao rememorar uma ideia expressa por Frei Betto a respeito do trabalho do pedagogo Paulo Freire:

No início e no fim do aprendizado é a práxis de Pedro que importa. Práxisteoria-práxis, num processo indutivo que torna $\mathrm{o}$ educando sujeito histórico. Pedro viu a uva e não viu a ave que, de cima, enxerga a parreira e não vê a uva. O que Pedro vê é diferente do que vê a ave. Assim, Paulo Freire ensinou a Pedro um princípio fundamental da epistemologia: a cabeça pensa onde os pés pisam. O mundo desigual pode ser lido pela ótica do opressor ou pela ótica do oprimido. Resulta uma leitura tão diferente uma da outra como entre a visão de Ptolomeu, ao imaginar-se com os pés no sol. (Frei, 1997, 23 julho).

A ideia "a cabeça pensa onde os pés pisam" se apresenta no desfecho da personagem de Udo Kier, ator que representa o sniper ariano, que é enterrado vivo no centro da cidade de Bacurau, para que o passado esteja sempre presente entre os cidadãos da cidade, para que a memória dos pés expresse os caminhos da mente; afinal, dentro da lógica exúlica essa postura é a mais assertiva e compreensível, uma vez que Exu matou um pássaro ontem com a pedra que jogou hoje.

Com a análise fílmica levantada ao longo do artigo, utilizando-se da lógica exúlica como metodologia de construção discursiva, buscando pontuar a dimensão estética-pedagógica do cinema a partir dessa obra, entende-se a relevância dessa pesquisa para a área de conhecimento. Pois, essa produção cinematográfica reflete, de fato, a justiça cognitiva, ao rever o que está posto historicamente, buscando a horizontalidade nas relações entre os que nasceram e habitam Bacurau, independente de idade/gênero/classe/raça, a fim de atingir uma circularidade de saberes, na ideia de ecologia de saberes de Boaventura de Sousa Santos (2007) para o enfrentamento contra aquele que se coloca a priori como "o outro".

E, uma vez que há no cinema uma dimensão estético-pedagógica, e que as produções fílmicas, próprias das mídias de massa, atuam - também - de forma considerável na educação informal ${ }^{\mathrm{ii}}$. Sendo 
Bacurau um filme de classificação indicativa a partir dos dezesseis anos de idade, crê-se que essa produção audiovisual pode atuar na formação de jovens, inscritos (ou não) no contexto do Ensino Médio, e por isso, é preciso que os professores estejam atentos às possibilidades discursivas que o filme facilita. Entendemos como resultado, portanto, que a produção audiovisual "Bacurau" tem aporte significativo para a formação de professores e estudantes. Reconhecendo a Educação como um organismo vivo do corpo social, que exige atenção para uma formação contínua, que se relaciona com a necessidade de sempre se atualizar discursivamente em todas as linguagens. E, considerando a classificação indicativa do filme, é possível que ele seja utilizado, inclusive, no contexto da educação formal, junto aos alunos da educação básica, no contexto do Ensino Médio, a fim de discutir as noções de centralidade e periferia, além de pautar a encruzilhada como lugar de possibilidades.

\section{Referências}

Abdala, V. (2019). Quatro municípios concentram $11,8 \%$ da população brasileira. Recuperado de: https://agenciabrasil.ebc.com.br/geral/notic ia/2019-08/quatro-municipios-concentram118-da-populacao-brasileira
Adorno, T. W., \& Horkheimer, M. (1947). Dialética do Esclarecimento. Recuperado de:

https://nupese.fe.ufg.br/up/208/o/fil_dialeti ca_esclarec.pdf

Almeida, R., \& Zmaberlan, C. (2020). Bacurau: Afirmação simbólica de um povo a se inventar. In Prudente, C. L., \& Silva, Batista, P. V. (Orgs.). $16^{\circ}$ Mostra Internacional de Cinema Negro Educação, Cultura e Semiótica (pp. 487509). São Paulo, SP: Jandaíra.

Azevedo, A. R. (2011). Inclusão digital e competência informacional: proposta de abordagem metodológica para estudo de usuários da informação digital. Múltiplos Olhares em Ciência da Informação, 1(1). Recuperado de https://periodicos.ufmg.br/index.php/moci/ article/view/16923

Bacurau. (2019). Direção: Juliano Dornelles, Kleber Mendonça Filho. Pernambuco: Vitrine Filmes, 2019 (131min).

Butler, J. (2019). Vida Precária - Os poderes da luta e da violência. Belo Horizonte, MG: Autêntica Editora.

Dondis, A. D. (1991). Sintaxe da linguagem visual. São Paulo, SP: Martins Fontes.

Frei B. (1997, 23 julho). Paulo Freire: $a$ leitura do mundo. Correio Riograndense.s/p.

Freire, P. (2013). Alfabetização: leitura do mundo, leitura da palavra. Rio de Janeiro, RJ: Paz e Terra.

Freire, P. (1971). Extensão ou comunicação? Rio de Janeiro, RJ: Paz e Terra. 
Freire, P. (1991). A educação na cidade. São Paulo, SP: Cortez.

Freire, P. (2014). Pedagogia da tolerância. 3. Rio de Janeiro, RJ: Paz e Terra.

Huizinga, J. (2010). Homo ludens: o jogo como elemento da cultura. São Paulo, SP: Perspectiva.

Mbembe, A. (2018). Necropolítica. São Paulo, SP: N-1.

Nascimento, A. (2019). O quilombismo: documentos de uma militância PanAfricanista. São Paulo, SP: Perspectiva.

Palma, A., Assis, M. R., \& Vilaça, (2019). Bacurau: Uma metáfora do Brasil Atual. Revista Práxis, 11(22), 31-36.

Prudente, C. L. (2019). A dimensão pedagógica da alegoria carnavalesca no cinema negro enquanto arte de afirmação ontológica da africanidade: pontos para um diálogo com Merleau-Ponty. In Prudente, C. L., \& Silva, D. C. (Orgs.). A dimensão pedagógica do cinema negro - Aspectos de uma arte para a afirmação ontológica do negro brasileiro: o olhar de Celso Prudente (pp. 113-136). São Paulo, SP: Anita Garibaldi.

Rufino, L., \& Simas, L. A. (2018). Fogo no Mato: a ciência encantada das macumbas. Rio de Janeiro, RJ: Mórula.

Rufino, L. (2019). Pedagogia das encruzilhadas. Rio de Janeiro, RJ: Mórula Editorial. https://doi.org/10.24065/22379460.2019v9n4ID1012

Santos, B. S. (2007). Para além do pensamento abissal: das linhas globais a uma ecologia de saberes. Novos Estudos CEBRAP 11(79), 71-94.
https://doi.org/10.1590/S010133002007000300004

Senghor, L. S. (1990). Oeuvre poétique. Paris: Éditions du Seuil.

Sirihal Duarte, A. B. (2007). Informação, sociedade e inclusão digital. In Reis, A. S., \& Cabral, A. M. (Orgs.) Informação, Cultura e Sociedade: interlocuções e perspectivas (pp. 101-121). Belo Horizonte, MG: Novatus.

Souza, E. L., \& Carvalho, A. F. (2021). O erê e o devir-criança negro: outros possíveis em tempos necropolíticos. Childhood \& Philosophy, 17, 01-28. https://doi.org/10.12957/childphilo.2021.5 6331.

Souza, E. G. L. (2016). Experiências de infâncias com produções de culturas no Ilê Axé Omo Oxé Ibá Latam (Tese de Doutorado). Universidade Federal de São Carlos, São Carlos.

Souza, E., \& Garcia, A. Jr. (no prelo). Brinco, logo me livro! Livro.

\footnotetext{
${ }^{\text {i }}$ Os quilombos apresentaram uma proposta sóciopolítica para o Brasil, elaborada pela cosmopercepção da população negra que habitavam esses territórios de re-existência. A esse respeito Nascimento define o quilombismo como ciência histórico-humanista. In Nascimento, A. (2019). O quilombismo: documentos de uma militância PanAfricanista. São Paulo: Perspectiva.

ii A educação informal pode ser entendida como processos formativos realizados ao longo da vida, a partir das experiências cotidianas, que se desenvolvem na família, no trabalho, no lazer e nas diversas mídias de massa (e o cinema, se insere como um dos produtos da indústria cultural, ou seja, uma das mídias de massa).
} 
No funding.

Como citar este artigo / How to cite this article

APA

Prudente, A. V. L. S., \& Souza, E. L. (2021). O Cinema e sua dimensão estético-pedagógica: Bacurau e a Lógica Exúlica. Rev. Bras. Educ. Camp., 6, e12372. http://dx.doi.org/10.20873/uft.rbec.e12372

ABNT

PRUDENTE, A. V. L. S.; SOUZA, E. L. O Cinema e sua dimensão estético-pedagógica: Bacurau e a Lógica Exúlica. Rev. Bras. Educ. Camp., Tocantinópolis, v. 6, e12372, 2021. http://dx.doi.org/10.20873/uft.rbec.e12372

Received on June 03th, 2021

Accepted on August 25th, 2021

Published on September, 30th, 2021

Contribuições no Artigo: As autoras foram as responsáveis por todas as etapas e resultados da pesquisa, a saber: elaboração, análise e interpretação dos dados; escrita e revisão do conteúdo do manuscrito e; aprovação da versão final publicada.

Author Contributions: The author were responsible for the designing, delineating, analyzing and interpreting the data, production of the manuscript, critical revision of the content and approval of the final version published.

Conflitos de Interesse: As autoras declararam não haver nenhum conflito de interesse referente a este artigo.

Conflict of Interest: None reported.

\section{Avaliação do artigo}

Artigo avaliado por pares.

\section{Article Peer Review}

Double review.

\section{Agência de Fomento}

Não tem.

\section{Funding}

\begin{tabular}{|l|l|l|l|l|l|l|} 
RBEC & Tocantinópolis/Brasil & v. 6 & e12372 & $10.20873 /$ uft.rbec.e12372 & 2021 & ISSN: 2525-4863 \\
\hline
\end{tabular}

